\title{
Acquired Perforating Osteoma Cutis
}

\author{
Bo-Kyung Kim ${ }^{1}$, Sung Ku Ahn ${ }^{1,2}$ \\ ${ }^{1}$ Department of Dermatology and ${ }^{2}$ Institute of Lifestyle Medicine, Yonsei University Wonju College of Medicine, Wonju, Korea
}

\begin{abstract}
Dear Editor:
Osteoma cutis is a rare, benign condition characterized by dermal or subcutaneous bone formation ${ }^{1}$ that presents as stony hard nodules ${ }^{2}$. Although the mechanism of bone formation remains unclear, it is speculated that resident fibroblasts or nests of pleuripotent mesenchymal cells differentiate into osteoblasts to form bone tissue ${ }^{2}$. This disease can be divided into two types according to origin. The primary type, which accounts for $15 \%$ of cases, occurs in the absence of predisposing factors. The secondary type, also known as the acquired type, occurs in cases involving preexisting inflammatory or neoplastic disease, or trauma ${ }^{2}$. Herein, we report a case of acquired perforating osteoma cutis probably due to chronic irritation.
\end{abstract}

A 40-year-old woman with diabetes mellitus had a solitary $1 \times 0.5-\mathrm{cm}$ erythematous nodule and central keratotic crater on her left breast for 20 years (Fig. 1). She reported that the lesion thickened and oozed fluid for 2 years. Laboratory test results for thyroid and parathyroid hormone were within normal limits. Mammography revealed solitary calcification at the same site, which was interpreted as a phlebolith. Excisional biopsy was performed for diagnosis and removal. The specimen had a central keratotic plug comprising osseous tissue with surrounding inflammatory cells (Fig. 2A) and bony nodules perforating the overlying epidermis (Fig. 2B). Von Kossa staining showed calcium deposition (Fig. 2C). On the basis of these findings, we diagnosed the patient with acquired perforating osteoma

Received July 23, 2013, Revised July 30, 2014, Accepted for publication August 12, 2014

Corresponding author: Sung Ku Ahn, Department of Dermatology and Institute of Lifestyle Medicine, Yonsei University Wonju College of Medicine, 20 Ilsan-ro, Wonju 220-701, Korea. Tel: 82-33-741-0621, Fax: 82-33-748-2650, E-mail: ahnsk@yonsei.ac.kr

This is an Open Access article distributed under the terms of the Creative Commons Attribution Non-Commercial License (http:// creativecommons.org/licenses/by-nc/4.0) which permits unrestricted non-commercial use, distribution, and reproduction in any medium, provided the original work is properly cited. cutis.

Perforation commonly occurs in perforating collagenosis, perforating folliculitis, granuloma annulare, and calcinosis cutis $^{1}$. Perforating osteoma cutis is a very rare condition; few cases have been reported ${ }^{1,3,4}$. Several potential mechanisms of perforation have been described: (a) transepidermal elimination, which is a dermal-induced epidermal reaction to eliminate foreign bodies, degenerated connective tissue or keratin, calcium deposits, and/or ectopic tissue ${ }^{5}$; (b) the pressure effect from underlying tissue $^{1}$; (c) simple upward growth of underlying tissue; and (d) superficial inflammation caused by external trauma, leading to the degeneration and perforation of the epidermis ${ }^{5}$. We speculate persistent irritation by brassieres might have induced superficial inflammation and stimulated the differentiation of cells into osteoblasts in the present case. Calcification occurred much later, and calcium-containing ectopic bone tissue induced transepidermal elimination. In addition, the pressure effect and

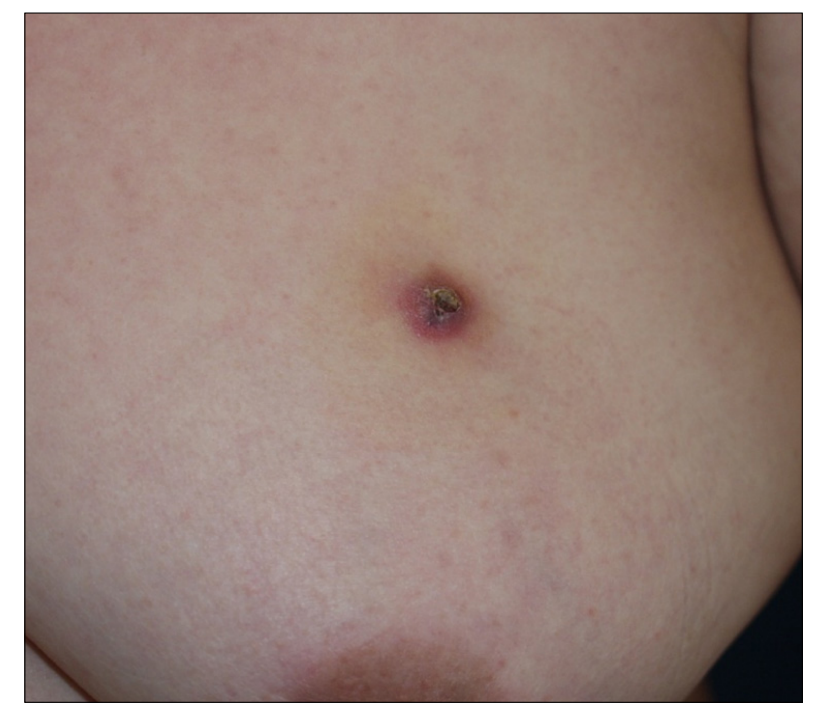

Fig. 1. A solitary, oozing, $1 \times 0.5-\mathrm{cm}$ erythematous papule and central keratotic crater on left the breast. 

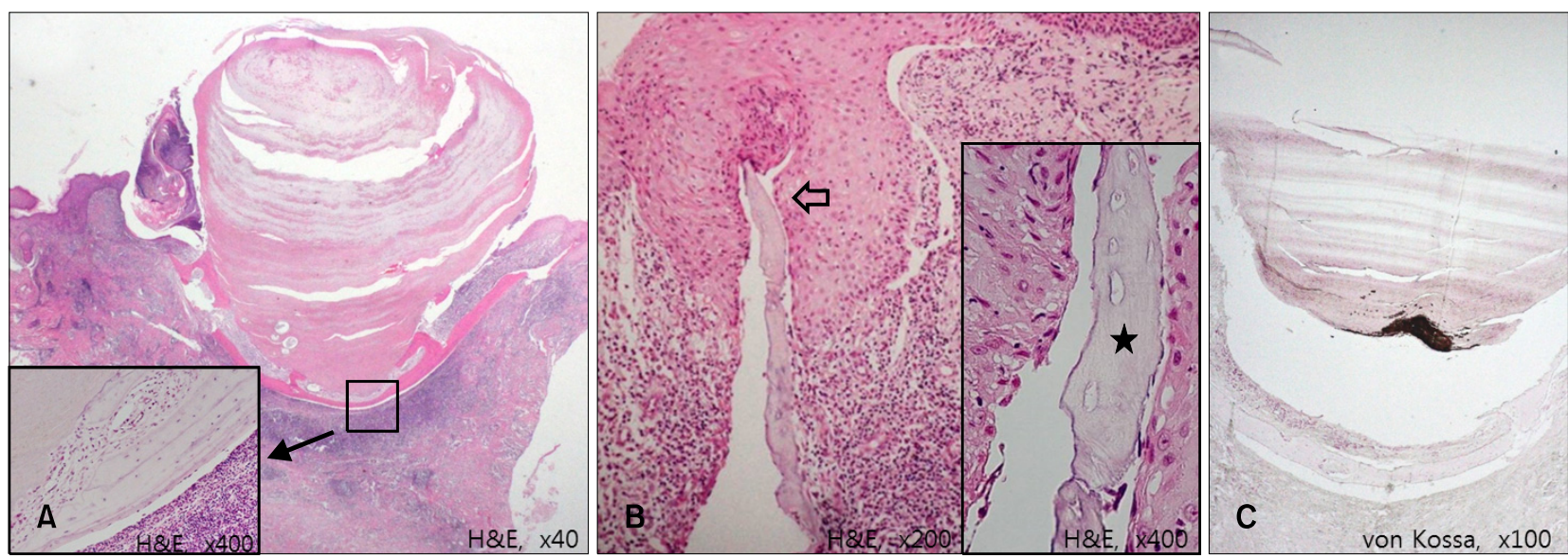

Fig. 2. (A) A central well-demarcated keratotic plug in the epidermis, granulomatous inflammation and fibrosis in the dermis (H\&E, $\times 40$ ). Inset: the calcified plug was composed of osteoblasts, osteoclasts, and osteocytes $(\mathrm{H} \& \mathrm{E}, \times 400)$. (B) Bony nodules (arrow) with inflammatory cell infiltration $(\mathrm{H} \& \mathrm{E}, \times 200)$. Inset: a bony spicule (asterisk) perforates the epidermis $(\mathrm{H} \& \mathrm{E}, \times 400)$. (C) Von Kossa staining revealed calcium deposition in the center of the lesion (von Kossa, $\times 100$ ).

simple upward growth of bony nodules might have facilitated epidermal perforation.

In the present case, the presence of clustered osseous tissue with surrounding dermal inflammatory cells supports the idea that the lesion was secondary to trauma ${ }^{3}$. Furthermore, von Kossa staining revealed calcium deposition, which indicates the chronic phase of ossification. Osteoma cutis is rare condition often misdiagnosed as thrombophlebitis on radiography. In the present case, a radiologist interpreted the calcification observed on mammography as a phlebolith. The accurate diagnosis of osteoma cutis requires histopathologic confirmation or bone scan.

Surgical removal is commonly performed to treat osteoma cutis $^{2}$. Our patient was successfully treated with excision, and no recurrence has been noted during 6 months of follow-up.

In summary, we report a case of secondary perforating osteoma cutis probably due to chronic irritation. Histopatho- logic confirmation of bone tissue or bone scan is required to establish a definite diagnosis of osteoma cutis.

\section{REFERENCES}

1. Hong SH, Kang HY. A case of perforating osteoma cutis. Ann Dermatol 2003;15:153-155.

2. Duarte IG. Multiple injuries of osteoma skin in the face: therapeutical least invasive in patients with acne sequelacase report. An Bras Dermatol 2010;85:695-698.

3. Grandhe N, Dogra S, Saikia U, Handa S. Acquired perforating primary osteoma cutis. Acta Derm Venereol 2004;84:489490.

4. Ahn SK, Won JH, Choi EH, Kim SC, Lee SH. Perforating plate-like osteoma cutis in a man with solitary morphoea profunda. Br J Dermatol 1996;134:949-952.

5. Woo TY, Rasmussen JE. Disorders of transepidermal elimination. Part 2. Int J Dermatol 1985;24:337-348. 